\title{
ANALISIS PENDAPATAN PETANI HHBK KAYU PUTIH (Melaleuca cajuputi) DI HUTAN LINDUNG DESA MONTONG SAPAH KECAMATAN PRAYA BARAT DAYA KABUPATEN LOMBOK TENGAH
}

Oleh:

\author{
Wulan Prafita Sari dan Yulia Ratnaningsih \\ Program Studi Kehutanan Universitas Pendidikan Mandalika
}

\begin{abstract}
Abstrak
Minyak kayu putih merupakan salah satu hasil hutan bukan kayu yang memiliki nilai ekonomi tinggi dan dapat dimanfaatkan untuk kehidupan sehari-hari. Saat ini permintaan minyak kayu putih diperkirakan akan terus meningkat dengan bertambahnya populasi penduduk dunia dan berkembangnya berbagai industri yang memanfaatkan minyak kayu putih. Tujuan penelitian ini adalah untuk mengetahui tingkat pendapatan, kelayakan usaha petani HHBK kayu putih (Melaleuca cajuputi) dan sistem pemasaran hasil panen kayu putih (Melaleuca cajuputi). Lokasi penelitian terletak di Hutan Lindung Desa Montong Sapah Kecamatan Praya Barat Daya Kabupaten Lombok Tengah Provinsi Nusa Tenggara Barat. Metode yang digunakan dalam penelitian ini adalah metode deskriptif, teknik pengumpulan data dilakukan dengan teknik survey dan wawancara dengan menggunakan alat bantu kuisioner terhadap 14 responden yang dilaksanakan pada bulan januari 2020. Penentuan responden dilakukan dengan random sebanyak 15\% dari jumlah petani HHBK kayu putih (Melaleuca cajuputi) yang tergabung dalam Kelompok Tani Hutan Tenem . Hasil penelitian ini menunjukkan bahwa tingkat pendapatan petani dalam kisaran waktu 1 tahun adalah sebesar Rp. 2.901.000, rata-rata tiap kali panen dalam kisaran waktu perdua bulan sebesar Rp. 792.000 dan tingkat kelayakan usaha dimana R/C Ratio menunjukkan 2,58 $\geq 1,3$ yang berarti menguntungkan, maka usaha ini layak dilanjutkan. Dalam analisis pemasaran menunjukkan bahwa petani menjual kayu putih ke satu tempat (monopoli) dengan 2 sistem pembayaran yang dilakukan oleh pihak pembeli yaitu $64 \%$ pembayaran langsung dan $36 \%$ pembayaran kemudian. Untuk meningkatkan pendapatan maka diharapkan petani meningkatkan usaha pemeliharaan seperti pemangkasan (prunning) sesuai petunjuk teknis kemudian perlu adanya campur tangan pemerintah untuk menentukan harga jual daun kayu putih ,mencari informasi pasar untuk mendapat nilai jual maksimal atau optimal dan frekuensi kerja penyuluh lebih ditingkatkan kembali
\end{abstract}

Keywords : HHBK Kayu Putih, Pendapatan, Kelayakan Usaha, Pemasaran, Desa Montong Sapah.

\section{PENDAHULUAN}

Pembangunan kehutanan merupakan salah satu bagian dari pembangunan nasional, yang diarahkan untuk memberikan manfaat yang sebesar-besarnya bagi kesejahteraan dan kemakmuran rakyat secara berkelanjutan. Melalui Permenhut No.19/Menhut-II/2009 Pemerintah telah mengamanatkan bahwa pembangunan kehutanan tidak lagi pada kayukayuan tetapi juga mengoptimalkan hasil hutan bukan kayu sebagai salah satu tujuan dalam pembangunan kehutanan di Indonesia dan dikembangkan menjadi sektor unggulan dalam industri kehutanan di masa yang akan datang.

Hasil Hutan Bukan Kayu yang selanjutanya disingkat HHBK sering juga disebut hasil hutan non kayu yang disingkat HHNK merupakan semua benda biologis termasuk jasa lingkungan yang berasal dari hutan atau tegakan hutan, kecuali produk berupa kayu. Hasil hutan bukan kayu terdiri dari benda-benda hayati yang berasal dari flora dan fauna. Selain itu termasuk juga jasa air, udara dan manfaat tidak langsung dari hutan (UU No.41 Tahun 1999). Hasil Hutan Bukan Kayu (HHBK) adalah hasil hutan hayati baik nabati juga hewani bersama produk turunannya dan budidaya kecuali kayu yang berasal dari hutan (Permenhut No.35 Tahun 2007).

Saat ini produk Hasil Hutan Bukan Kayu (HHBK) sedang menjadi perhatian khusus bagi pemerintah karena memiliki keunggulan komparatif dan paling bersinggungan dengan masyarakat sekitar hutan. Secara ekonomis, HHBK berpotensi dapat memberikan dampak pada peningkatan penghasilan masyarakat sekitar hutan dan memberikan kontribusi bagi 
devisa negara. Hasil hutan bukan kayu yang sedang dikembangkan dan menjadi prioritas oleh Dinas Lingkungan Hidup dan Kehutanan Provinsi NTB salah satunya adalah tanaman kayu putih (Melaleuca cajuputi). Saat ini permintaan minyak kayu putih diperkirakan akan terus meningkat dengan bertambahnya populasi penduduk dunia dan berkembangnya berbagai industri yang memanfaatkan minyak kayu putih. Menurut Rimbawanto et al. (2017) kebutuhan minyak kayu putih di dalam negeri saat ini mencapai 3500 ton per tahunnya. Minyak kayu putih merupakan salah satu hasil hutan bukan kayu yang memiliki nilai ekonomi tinggi dan dapat dimanfaatkan untuk kehidupan sehari-hari. Minyak kayu putih ini dikelola oleh KPH khususnya di BKPH Rinjani Barat Pelangan Tastura. BKPH Rinjani Barat Pelangan Tastura melibatkan masyarakat sekitar hutan sebagai tenaga kerja penyulingan minyak kayu putih, dengan adanya keterlibatan ini diharapkan ada peningkatan produktivitas. Pengembangan budidaya tanaman kayu putih telah dilakukan dibeberapa kawasan hutan pengelolaan BKPH Rinjani Barat Pelangan Tastura.

Desa Montong Sapah Kecamatan Praya Barat Daya Kabupaten Lombok Tengah merupakan salah satu lokasi pengembangan budidaya tanaman kayu putih (Melaleuca cajuputi) tepatnya di Dusun Puri Mandana. Pengembangan dan budidaya tanaman ini dilakukan di Hutan Lindung Montong Sapah RTK 13 Kelompok Hutan Mareje Bonga seluas 100 ha. Masyarakat khususnya yang tinggal di sekitar kawasan hutan kini dapat merasakan dampak positif dengan adanya pengembangan tanaman kayu putih (Melaleuca cajuputi) yaitu menambah pendapatan rumah tangga. Untuk itu, perlu adanya penelitian tentang Analisis Pendapatan Petani HHBK Kayu Putih (Melaleuca cajuputi) di Hutan Lindung Desa Montong Sapah Kecamatan Praya Barat Daya Kabupaten Lombok Tengah.

Oleh karena itu penelitian ini bertujuan untuk

Mengetahui tingkat pendapatan petani kayu putih, tingkat kelayakan usaha dan sistem serta cara pemasaran hasil kayu putih (Melaluca cajuputi) di Hutan Lindung Desa Montoh Sapah, Kecamatan Praya Barat Daya Kabupaten Lombok Tengah.

\section{METODOLOGI PENELITIAN}

a. Metode dan Teknik Penelitian
Metode yang digunakan dalam penelitian ini adalah metode deskriftif yaitu metode mengumpulkan, menyusun dan menganalisa serta mengintepretasikan data kemudian menarik kesimpulan. Menurut Sugiyono (2009) metode deskriptif adalah metode yang digunakan untuk menggambarkan atau menganalisis suatu hasil penelitian tetapi tidak digunakan untuk membuat kesimpulan yang lebih luas.

Pengumpulan data dilakukan dengan teknik survey dan wawancara menggunakan daftar pertanyaan atau kuisioner yang telah disiapkan sebelumnya..

\section{b. Waktu dan Lokasi Penelitian}

Penelitian ini dilakukan pada kelompok tani hutan tenem yang berada di Desa Montong Sapah, Kecamatan Praya Barat Daya, Kabupaten Lombok Tengah dan dilaksanakan selama satu bulan yaitu pada bulan Januari 2020 .

\section{c. Bahan dan Alat Penelitian}

Alat dan bahan yang digunakan dalam penelitian ini adalah : alat tulis dan buku, kamera digital atau handphone, komputer.

\section{d. Penentuan Responden}

Penentuan responden dilakukan dengan random, yang diambil 15\% dari total populasi 94 orang, maka diperoleh 14 responden. Populasi dalam penelitian ini adalah semua masyarakat yang memanfaatkan hhbk kayu putih di Hutan Lindung Desa Montong Sapah.

\section{e. Jenis Data}

Jenis data yang digunakan adalah data kuantitatif dan kualitatif. Dan menurut sumbernya data penelitian ini terdiri dari data primer dan sekunder.

\section{f. Variabel dan Cara Pengukuran}

Beberapa variabel yang sudah diidentifikasi dan dapat didefinisikan sebagai berikut :

1. Produksi adalah hasil panen dan semua jenis pengolahan dari tanaman kayu putih.

2. Total penerimaan adalah jumlah penerimaan dari penjualan hasil produksi dengan cara mengalikan hasil produksi dengan harga penjualan dalam satuan rupiah $(\mathrm{Rp})$.

3. Total pengeluaran adalah keseluruhan pengeluaran yang terdiri dari biaya tetap, biaya variabel, dan biaya pemasaran yang dinyatakan dalam satuan rupiah ( $\mathrm{Rp})$. 
4. Pendapatan petani adalah pendapatan yang diperoleh petani selama satu musim setelah dikurangi dengan biaya, yang dinyatakan dalam satuan rupiah (Rp).

5. Sistem pemasaran adalah kumpulan lembaga-lembaga yang melakukan tugas pemasaran barang, jasa, ide, orang, dan faktor-faktor lingkungan yang saling memberikan pengaruh dan membentuk serta mempengaruhi hubungan perusahaan dengan pasarnya.

6. Cara pemasaran adalah upaya memasarkan suatu produk, baik itu barang atau jasa, dengan cara langsung ke pabrikan atau melalui perantara secara oarang perorang atau sehingga jumlah penjualan menjadi lebih tinggi. Jadi lebih baik penjualan secara langsung kepada pabrikan berskala kelompok.

\section{g. Teknik Analsis Data}

Data yang diperoleh disusun dan diolah kemudian disajikan dalam bentuk tabel.

Untuk mengetahui tingkat pendapatan petani hhbk kayu putih, komponen-komponen yang dihitung adalah sebagai berikut :

1. Total penerimaan :

$$
\mathbf{T R}=\mathbf{P} \times \mathbf{Q}
$$

Dimana :

TR :Total Revenue :Penerimaan Kotor

$\mathrm{P}$ : Price :Harga Satuan Produk

Q : Quantum :Volume/Jumlah Produksi

2. Total pengeluaran

$$
\mathbf{T C}=\mathbf{F C}+\mathbf{V C}
$$

Dimana :

TC :Total Cost

:Total Biaya

FC : Fixel Cost

:Biaya Tetap

VC : Variable Cost

:Biaya Tidak Tetap

3. Pendapatan bersih

$$
\mathbf{I}=\mathbf{T R} \text { - TC }
$$

Dimana :

I :Income :Pendapatan Bersih

TR : Total Revenue :Penerimaan Kotor

TC : Total Cost :Total Biaya

\section{R/C Ratio}

$$
\mathrm{R} / \mathrm{C} \text { Ratio }=\frac{\text { Total Penerimaan }}{\text { Total Pengeluaran }} \times 100 \%
$$

Dimana :

$\begin{array}{ll}\text { Bila R/C Ratio } \geq 1,3 & : \text { Layak } \\ \text { Bila R/C Ratio } \leq 1,3 & : \text { Tidak Layak /Rugi } \\ \text { Bila R/C Ratio } 1 \leq 1,3 & \text { : Break Event Point }\end{array}$

5. Nilai Penyusutan

$$
\mathrm{D}=\frac{\mathrm{A}-\mathrm{S}}{\mathrm{n}}
$$

Dimana :

D : Nilai Penyusutan

A : Nilai Perolehan Alat

S : Perkiraan Nilai Sisa

$\mathrm{n}$ : Usia Pakai

6. Untuk menghitung ongkos tenaga kerja dengan HOK (Harian Orang Kerja):

$\begin{array}{ll}\text { Laki-laki } 1 \text { hari } & : 1 \mathrm{HOK} \\ \text { Perempuan } 1 \text { hari } & : 0,8 \mathrm{HOK} \\ \text { Anak - anak } 1 \text { hari } & : 0,6 \mathrm{HOK}\end{array}$

Analisis pemasaran dilakukan dengan menggunakan teknik snowball sampling (bola salju) yaitu metode sampling di mana sampel diperoleh melalui proses bergulir dari satu responden ke responden yang lain. Teknik snowball sampling yang dilakukan yaitu dengan melakukan wawancara secara mendalam kepada lembaga pemasaran yang terlibat didalam pemasaran kayu putih.

\section{HASIL dan PEMBAHASAN}

\section{a. Wilayah dan Topografi}

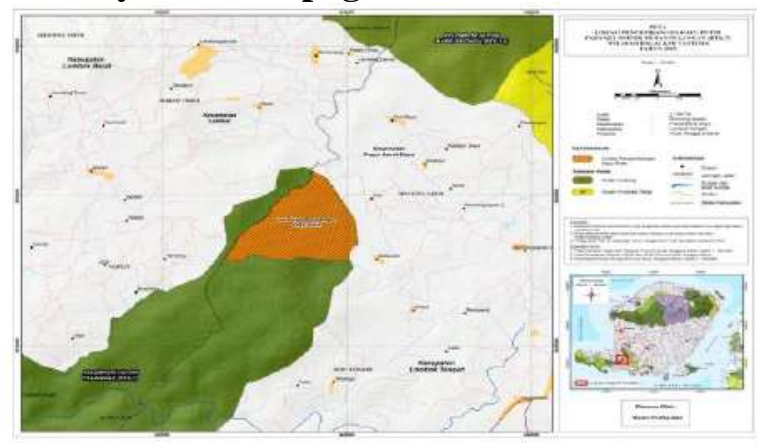

Gambar 1. Peta Lokasi Penelitian

Desa Montong memiliki luas $1.253,15 \mathrm{Ha}$ yang terdiri dari 14 Dusun yaitu Dusun anak Anjan, Dusun Kelanjur 1, Dusun Kelanjur II, Dusun Montong Sapah I, Montong Sapah II, Dusun Karang Dalam, Dusun Puri Mandana, Dusun Kuwur Numpuk, Dusun Batu Nebeng, Dusun Batu Putik, Dusun Kebun Jeruk, Dusun 
Bukit Maun, Dusun Bentang dan Dusun Montong Sidu.

Batas-batas wilayah Desa Montong Sapah adalah sebagai berikut:

Sebelah Utara : Desa Serage

Sebelah Selatan : Desa Batu Jangkih

Sebelah Timur : Desa Kabul

Sebelah Barat : Desa Mareje Timur

Kabupaten Lombok Barat

Lokasi penelitian terletak di Hutan Lindung Desa Montong Sapah Kecamatan Praya Barat Daya Kabupaten Lombok Tengah. Lokasi ini merupakan lahan garapan kelompok tani hutan tenem. Tanaman kayu putih tumbuh subur di lahan garapan. Kelompok tani hutan tenem telah melakukan penanaman dan pemeliharaan tanaman kayu putih. Tanaman ini merupakan program rehabilitasi hutan dan lahan yang dilakukan oleh Balai Pengelolaan Daerah Aliran Sungai seluas 100 ha yang kini dimanfaatkan oleh kelompok tani hutn tenem. Kayu putih di Hutan Lindung Desa Montong Sapah sudah dapat dipanen saat berumus 2,5 tahun. Pemanenan kayu putih dilakukan dengan cara memangkas dau beserta ranting kayu dengan menggunakan parang atau sabit. Kemudian hasil panennya dikumpulkan di rumah ketua kelompok. Kegiatan ini dilakukan petani hanya sebagai pekerjaan sampingan karena sebagian besar petani memiliki pekerjaan utamanya yaitu bertani, berkebun dan beternak.

Desa Montong Sapah, diketahui untuk penggunaan lahan persawahan sebesar 41,00 Ha, lahan tegal atau ladang $37,00 \mathrm{Ha}$, pemukiman 52,00 Ha, lahan pekarangan sebesar 245,00 Ha, untuk tanah rawa, pasang surut, lahan gambut, waduk atau danau dan tanah kas desa $0,00 \mathrm{Ha}$, untuk perkebunan $375,00 \mathrm{Ha}$, fasilitas umum sebesar 3,15 Ha dan untuk Lahan hutan sebesar $500 \mathrm{Ha}$.

Dilihat dari topografinya, Desa Montong Sapah memiliki iklim tropis, dan termaasuk dataran rendah dengan kondisi tanah yang berbukit-bukit dan juga lereng. Desa Montong Sapah pada ketinggian 105,00 meter di atas permukaan laut dengan tingkat curah hujan 5,00 mm perbulan.

Jenis tanah di Desa Montong Sapah pada umumnya adalah tanah liat dan mempunyai tekstur tanah yang debuan. Tanaman pangan yang banyak terdapat di daerah ini adalah padi, jagung dan kacang-kacangan. Sedangkan untuk tanaman perkebunan banyak terdapat tanaman kelapa, mangga, nangka dan lain-lain.
Tabel 1. Luas Wilayah Desa Montong Sapah Menurut Penggunaannya Pada Tahun 2019.

\begin{tabular}{llr}
\hline No. & Penggunaan & Luas Areal (Ha) \\
\hline 1 & Persawahan & 41,00 \\
\hline 2 & Tegal/Ladang & 37,00 \\
\hline 3 & Pemukiman & 52,00 \\
\hline 4 & Pekarangan & 245,00 \\
\hline 5 & Tanah Rawa & 0,00 \\
\hline 6 & Pasang Surut & 0,00 \\
\hline 7 & Lahan Gambut & 0,00 \\
\hline 8 & Situ/Waduk/Danau & 0,00 \\
\hline 9 & Perkebunan & 375,00 \\
\hline 10 & Tanah Kas Desa & 0,00 \\
\hline 11 & Fasilitas Umum & 3,15 \\
\hline 12 & Hutan & 500,00 \\
\hline & Total Luas & $1.253,15$ \\
\hline
\end{tabular}

Sumber :Buku Profil Desa Montong Sapah 2019

Penduduk Desa Montong Sapah sebagian besar bekerja sebagai petani dan buruh petani. Jumlah penduduk Desa Montong Sapah yang bekerja sebagai petani sebanyak 749 orang sedangkan buruh petani sebanyak 632 orang, untuk penduduk yang bekerja sebagai buruh migran sebanyak 262 orang, sebagai montir sebanyak 2 orang, dokter swasta sebanyak 1 orang, sebagai perawat swasta 5 orang, bidan swasta sebanyak 2 orang, yang menjadi TNI sebanyak 1 orang, yang menggeluti UKM sebanyk 65 orang, sebagai dosen swasta 2 orang, pedagang keliling 15 orang, sebagai dukun tradisional 12 orang dan sebagai pengrajin industri rumah tangga sebanyak 35 orang.

Tabel 2. Susunan Penduduk Desa Kabul Berdasarkan Mata Pencaharian Tahun 2019

\begin{tabular}{|c|c|c|c|c|}
\hline No. & $\begin{array}{l}\text { Mata } \\
\text { Pencaharian }\end{array}$ & $\begin{array}{r}\text { Laki- } \\
\text { laki }\end{array}$ & Perempuan & Jmlh \\
\hline 1 & Petani & 407 & 342 & 749 \\
\hline 2 & Buruh Tani & 382 & 250 & 632 \\
\hline 3 & Buruh Migran & 2399 & 23 & 262 \\
\hline 4 & Montir & 2 & 0 & 2 \\
\hline 5 & Dokter Swasta & 1 & 0 & 1 \\
\hline 6 & Perawat Swasta & 4 & 1 & 5 \\
\hline 7 & Bidan Swasta & 0 & 2 & 2 \\
\hline 8 & TNI & 1 & 0 & 1 \\
\hline 9 & UKM & 10 & 55 & 65 \\
\hline 10 & Dosen Swasta & 2 & 0 & 2 \\
\hline 11 & $\begin{array}{l}\text { Pedagang } \\
\text { Keliling }\end{array}$ & 3 & 12 & 15 \\
\hline 12 & $\begin{array}{l}\text { Dukun } \\
\text { Tradisional } \\
\text { Pengrajin }\end{array}$ & 1 & 11 & 12 \\
\hline \multirow[t]{2}{*}{13} & $\begin{array}{l}\text { Industri Rumah } \\
\text { Tangga }\end{array}$ & 5 & 30 & 35 \\
\hline & Total Orang & 1.057 & 72 & 1.783 \\
\hline
\end{tabular}

Sumber :Buku Profil Desa Montong Sapah 2019 


\section{b. Karakteristik Responden Umur Responden}

Tabel.3 Karakteristik Responden Petani Kayu Putih (Melaleuca cajuputi) Di Desa Montong Sapah Berdasarkan Umur Produktif.

\begin{tabular}{lccc}
\hline No. & Umur Petani & Jumlah & Persentase \\
\hline 1 & $21-30$ & 3 & $21,43 \%$ \\
2 & $31-40$ & 0 & $0,00 \%$ \\
3 & $41-50$ & 4 & $28,57 \%$ \\
4 & $>50$ & 7 & $50 \%$ \\
\hline \multicolumn{2}{c}{ Jumlah } & \multicolumn{1}{c}{14} & $100 \%$ \\
\hline
\end{tabular}

Sumber : Data Primer (Diloah, 2020)

Berdasarkan dari hasil wawancara diketahui bahwa responden dari kelompok tani hutan tenem di dominasi oleh kelompok masyarakat yang berusia lebih dari 50 tahun yaitu sebesar $50 \%$. Berdasarkan informasi tersebut terlihat bahwa masyarakat yang memanfaatkan sumber daya hutan berupa hhbk kayu putih terbesar dilkukan oleh kelompok produktif.

\section{Tingkat Pendidikan}

Tingkat pendidikan masyarakat dapat berpengaruh terhadap tingkat pemanfaatan sumberdaya hutan. Hal ini terkait dengan ilmu pengetahuan yang dimiliki, penguasaan teknologi, ketrampilan dan informasi pasar yang diperoleh. Dengan ilmu pengetahuan, penguasaan teknologi, ketrampilan dan informasi pasar yang rendah menyebabkan pemanfaatan hhbk kayu putih yang kurang maksimal. Berdasarkan hasil wawancara diketahui bahwa tingkat pendidikan petani responden pada umumnya masih tergolong rendah. Hal ini terlihat dari sebagian besar petani responden yang hanya menempuh jenjang pendidikan tingkat SD yaitu $57,14 \%$. Kondisi ini tentunya mengakibatkan ketergantungan masyarakat terhadap terhadap sumberdaya hutan menjadi sangat besar.

Tabel. 3 Karakteristik Responden Petani Kayu Putih (Melaleuca cajuputi) Di Desa Montong Sapah Berdasarkan Tingkat Pendidikan.

\begin{tabular}{clcc}
\hline $\mathrm{N}$ & Tingkat Pendidikan & $\begin{array}{c}\text { Jumlah } \\
\text { (Orang) }\end{array}$ & $\begin{array}{c}\text { Persentase } \\
(\%)\end{array}$ \\
\hline 1 & $\begin{array}{l}\text { Sekolah Dasar (SD) } \\
2\end{array}$ & 8 & $57,14 \%$ \\
2 & $\begin{array}{l}\text { Sekolah Menengah } \\
\text { Pertama (SMP) }\end{array}$ & 4 & $28,57 \%$ \\
3 & $\begin{array}{l}\text { Sekolah Menengah Atas } \\
\text { (SMA) }\end{array}$ & 2 & $14,29 \%$ \\
\hline Jumlah & 14 & $100 \%$ \\
\hline
\end{tabular}

Sumber : Data Primer (Diloah, 2020)

\section{Kepemilikan Lahan}

Untuk status kepemilikan lahan petani responden di Desa Montong Sapah dibedakan menjadi 4 yaitu lahan pribadi, lahan sewa, lahan adat dan lainnya (lahan atas hak kelola). Ratarata semua petani responden di daerah penelitian menggarap lahan atas hak kelola. Pada umumnya lahan petani responden seluas 1,00 ha sebanyak 13 orang atau $92,86 \%$.

Tabel. 4 Karakteristik Responden Petani Kayu Putih (Melaleuca cajuputi) Di Desa Montong Sapah Berdasarkan Luas Lahan Yang Dimiliki.

\begin{tabular}{cccc}
\hline No. & $\begin{array}{c}\text { Luas Lahan } \\
(\mathrm{Ha})\end{array}$ & $\begin{array}{c}\text { Jumlah } \\
\text { (Orang) }\end{array}$ & $\begin{array}{c}\text { Persentase } \\
(\%)\end{array}$ \\
\hline 1 & 0,50 & 1 & $7,14 \%$ \\
2 & 0,70 & 1 & $7,14 \%$ \\
2 & 1,00 & 13 & $85,72 \%$ \\
& Jumlah & 14 & $100 \%$ \\
\hline
\end{tabular}

Sumber : Data Primer (Diloah, 2020)

\section{c. Analisis Pendapatan Petani Kayu Putih (Melaleuca cajuputi)}

Biaya produksi adalah semua biaya atau modal baik yang dibayar tunai maupun yang tidak dibayar tunai selama proses kegiatan berlangsung. Biaya tunai adalah Biaya tunai adalah biaya yang dikeluarkan secara nyata dalam pemanenan kayu putih di hutan terdiri atas biaya untuk membeli alat dan perlengkapan dalam melakukan pemanenan serta upah tenaga kerja dari dalam dan luar keluarga. Biaya tidak tunai yaitu yang tidak dikeluarkan secara langsung tetapi diperhitungkan (Hermanto, 1993).

Tabel. 5 Rata-rata Biaya Yang Dikeluarkan Petani Kayu Putih Di Desa Montong Sapah.

\begin{tabular}{cccr}
\hline $\begin{array}{c}\text { No. } \\
\text { Resp }\end{array}$ & $\begin{array}{c}\text { Total } \\
\text { Penyusutan } \\
(\mathrm{Rp})\end{array}$ & $\begin{array}{c}\text { Tenaga } \\
\text { Kerja } \\
(\mathrm{Rp})\end{array}$ & $\begin{array}{c}\text { Total } \\
\text { Pengeluaran / } \\
\text { TC (Rp) }\end{array}$ \\
\hline 1 & 66.000 & 380.000 & 446.000 \\
2 & 38.000 & 230.000 & 268.000 \\
3 & 42.000 & 300.000 & 342.000 \\
4 & 38.000 & 300.000 & 338.000 \\
5 & 21.000 & 300.000 & 321.000 \\
6 & 68.000 & 230.000 & 298.000 \\
7 & 32.000 & 300.000 & 332.000 \\
8 & 36.000 & 300.000 & 336.000 \\
9 & 42.000 & 230.000 & 272.000 \\
10 & 44.000 & 300.000 & 344.000 \\
11 & 34.000 & 300.000 & 334.000 \\
12 & 29.000 & 150.000 & 179.000 \\
13 & 28.000 & 300.000 & 328.000 \\
14 & 42.000 & 150.000 & 192.000 \\
Jmlh & 560.000 & 3.770 .000 & 4.330 .000 \\
Rata2 & 40.000 & 269.000 & 309.000 \\
\hline \multicolumn{3}{c}{ Sumber : Data Primer (Diloah, 2020) }
\end{tabular}


Untuk rata-rata biaya produksi yang harus dikeluarkan dalam kegiatan pemeliharaan tanaman kayu putih untuk enam kali panen dalam setahun atau perdus bulsn yang meliputi biaya alat dan perlengkapan biaya tenaga kerja adalah sebesar Rp. 309.000,00

\section{Produksi dan Harga Jual}

Jumlah produksi kayu putih yang dihasilkan oleh petani responden tergantung banyaknya pohon yang ditanam di lahan garapan petani dan sistem pemeliharan yang intensif. Produksi merupakan salah satu faktor yang menentukan besar kecilnya laba / keuntungan yang akan diterima oleh para petani.

Berdasarkan dari hasil analisis produksi dan harga jual kayu putih, dapat diketahui total luas lahan responden di lokasi penelitian sebesar 13,20 Ha dengan rata-rata luas lahan untuk satu orang responden 1 ha dan produksi kayu putih mencapai $500-1000$ kilogram/ha. Jumlah produksi kayu putih untuk satu orang petani responden rata-rata mencapai 792 kilogram dengan harga jual rata-rata sebesar $\mathrm{Rp}$. $1.000 / \mathrm{Kg}$, sehingga diperoleh penerimaan ratarata sebesar Rp. 792.000 per 2 bulan.

Tabel. 6. Rata-rata Nilai Produksi Dan Harga Jual Kayu Putih Di Desa Montong Sapah.

\begin{tabular}{crrrr}
\hline & \multicolumn{4}{c}{ Produksi Kayu Putih } \\
\cline { 2 - 5 } No. & $\begin{array}{c}\text { Kilo } \\
\text { gram } \\
\text { (Kg) }\end{array}$ & Bln & $\begin{array}{c}\text { Harga } \\
\text { Jual } \\
(\mathrm{Rp})\end{array}$ & $\begin{array}{c}\text { Total } \\
\text { Penerimaan } \\
(\mathrm{TR})(\mathrm{Rp})\end{array}$ \\
\hline 1 & 1.000 & 2 & 1.000 & 1.000 .000 \\
2 & 600 & 2 & 1.000 & 600.000 \\
3 & 900 & 2 & 1.000 & 900.000 \\
4 & 1.000 & 2 & 1.000 & 1.000 .000 \\
5 & 1.000 & 2 & 1.000 & 1.000 .000 \\
6 & 900 & 2 & 1.000 & 900.000 \\
7 & 700 & 2 & 1.000 & 700.000 \\
8 & 850 & 2 & 1.000 & 850.000 \\
9 & 700 & 2 & 1.000 & 700.000 \\
10 & 750 & 2 & 1.000 & 750.000 \\
11 & 900 & 2 & 1.000 & 900.000 \\
12 & 500 & 2 & 1.000 & 500.000 \\
13 & 800 & 2 & 1.000 & 800.000 \\
14 & 500 & 2 & 1.000 & 500.000 \\
Jmlh & 11.100 & & & 11.100 .000 \\
Rata2 & 792 & & 792.000 \\
\hline \multicolumn{5}{c}{ Sumber : Data Primer (Diloah, 2020) }
\end{tabular}

\section{Pendapatan dan Keuntungan}

Dari hasil analisis pendapatan, diperoleh data untuk rata-rata penerimaan tunai yang diperoleh petani responden di Desa Montong Sapah dari hasil panen kayu putih adalah sebesar Rp. 792.000 / ha. Jika dilihat secara keseluruhan untuk rata-rata total biaya yang dikeluarkan petani di Desa Montong Sapah adalah sebesar Rp. 309.000/ha. Dari hasil analisis dapat diketahui untuk pendapatan atau keuntungan terendah yang diterima petani responden adalah sebesar Rp. 308.000, dan untuk penerimaan tertinggi adalah sebesar Rp. 679.000.

Tabel. 7 Pendapatan Atau Keuntungan Petani Kayu Putih Di Desa Montong Sapah

\begin{tabular}{clcl}
\hline No. Resp & $\begin{array}{c}\text { Total } \\
\text { Penerimaan } \\
(\mathrm{Rp})\end{array}$ & $\begin{array}{c}\text { Total } \\
\text { Pengeluaran } \\
(\mathrm{Rp})\end{array}$ & Income (I) \\
\hline 1 & 1.000 .000 & 446.000 & 554.000 \\
2 & 600.000 & 268.000 & 332.000 \\
3 & 900.000 & 342.000 & 558.000 \\
4 & 1.000 .000 & 338.000 & 662.000 \\
5 & 1.000 .000 & 321.000 & 679.000 \\
6 & 900.000 & 298.000 & 602.000 \\
7 & 700.000 & 332.000 & 368.000 \\
8 & 850.000 & 336.000 & 514.000 \\
9 & 700.000 & 272.000 & 428.000 \\
10 & 750.000 & 344.000 & 406.000 \\
11 & 900.000 & 334.000 & 566.000 \\
12 & 500.000 & 179.000 & 321.000 \\
13 & 800.000 & 328.000 & 472.000 \\
14 & 500.000 & 192.000 & 308.000 \\
Jmlh & 11.100 .000 & 4.330 .000 & 6.770 .000 \\
Rata2 & 792.000 & 309.000 & 483.000 \\
\hline \multicolumn{5}{l}{ Sumber $:$ Data Primer $($ Diloah, 2020) }
\end{tabular}

\section{Analisis R/C Ratio}

Analisis R/C Ratio merupakan alat analisis yang digunakan untuk menyatakan kelayakan suatu kegiatan, apakah kegiatan usaha tersebut menguntungkan, balik modal atau merugikan. Suatu kegiatan dikatakan layak dan memberikan manfaat apabila nilai $\mathrm{R} / \mathrm{C}$ ratio $>1$, jika semakin besar nilai keuntungan atas biaya maka semakin besar pula manfaat yang akan diperoleh dari kegiatan tersebut, sedangkan jika nilai $\mathrm{R} / \mathrm{C}$ rationya tidak lebih \pm 1 , maka kegiatan tersebut dikatakan impas atau tidak menguntungkan atau merugikan.

Berdasarkan hasil perhitungan R/C Ratio di atas, maka dapat diketahui bahwa jika rata-rata penerimaan yang diperoleh petani responden di wilayah penelitian sebesar Rp.792.000 dan jika rata-rata biaya tetap, yaitu biaya alat dan perlengkapan maupun biaya tenaga kerja yang harus dikeluarkan petani responden sebesar Rp. 309.000, maka dapat diperoleh nilai R/C Ratio dengan rata-rata sebesar 2,58. Artinya, setiap Rp. 1 yang dikeluarkan oleh petani untuk biaya kegiatan , maka akan menghasilkan keuntungan sebesar 2.58 persen, karena nilai R/C Ratio lebih 
besar dari pada 1 (R/C > 1), maka dalam melakukan kegiatan budidaya kayu putih untuk pendapatan sampingan ini dapat dikatakan layak untuk diusahakan. Dengan demikian, bila petani menambah tanaman kayu putih semakin banyak maka keuntungan yang diperoleh akan semakin besar.

Tabel. 8 Analisis Kelayakan Petani Kayu Putih di Desa Montong Sapah

\begin{tabular}{|c|c|c|c|c|c|}
\hline No. Resp & $\begin{array}{c}\text { Total } \\
\text { Penerimaan } \\
(\mathrm{Rp})\end{array}$ & $\begin{array}{c}\text { Total } \\
\text { Pengeluaran } \\
\text { (Rp) }\end{array}$ & Income (I) & R/C Ratio & Ket \\
\hline 1 & 1.000 .000 & 446.000 & 554.000 & 2,24 & Layak \\
\hline 2 & 600.000 & 268.000 & 332.000 & 2,24 & Layak \\
\hline 3 & 900.000 & 342.000 & 558.000 & 2,63 & Layak \\
\hline 4 & 1.000 .000 & 338.000 & 662.000 & 2,96 & Layak \\
\hline 5 & 1.000 .000 & 321.000 & 679.000 & 3,12 & Layak \\
\hline 6 & 900.000 & 298.000 & 602.000 & 3,02 & Layak \\
\hline 7 & 700.000 & 332.000 & 368.000 & 2,11 & Layak \\
\hline 8 & 850.000 & 336.000 & 514.000 & 2,53 & Layak \\
\hline 9 & 700.000 & 272.000 & 428.000 & 2,57 & Layak \\
\hline 10 & 750.000 & 344.000 & 406.000 & 2,18 & Layak \\
\hline 11 & 900.000 & 334.000 & 566.000 & 2,69 & Layak \\
\hline 12 & 500.000 & 179.000 & 321.000 & 2,79 & Layak \\
\hline 13 & 800.000 & 328.000 & 472.000 & 2,44 & Layak \\
\hline 14 & 500.000 & 192.000 & 308.000 & 2,60 & Layak \\
\hline Jumlah & 11.100 .000 & 4.330 .000 & 6.770 .000 & 36,12 & \\
\hline Rata-rata & 792.000 & 309.000 & 483.000 & 2,58 & \\
\hline
\end{tabular}

Sumber : Data Primer (Di olah, 2020)

\section{Pemasaran Daun Kayu Putih}

Pemasaran daun kayu putih di desa Montong Sapah dilakukan dengan cara petani menjual langsung ke pabrik milik BKPH Rinjani Barat Pelangan Tastura. Karena seluruh petani hanya menjual langsug ke pabrik dan pabrik itu hanya satu-satunya yanng berada di Pulau Lombok maka pihak pabrik memonopoli harga daun kayu putih tersebut.

Karena hanya menjual ke satu tempat ( monopoli) maka tidak ada rantai pasar pada pemasaran daun kayu putih ini, atau biasa di sebut pemasaran langsung. Adapun sistem pembayaran yang dilakukan adalah pembayaran langsung sebanyak 9 petani responden atau $64 \%$ dan pembayaran kemudian sebanyak 5 petani responden atau $36 \%$.
Tabel. 9 Pemasaran Daun Kayu Putih Di Desa Montong Sapah

\begin{tabular}{|c|c|c|c|}
\hline No. Resp & Nama & $\begin{array}{c}\text { Pembayaran } \\
\text { Langsung }\end{array}$ & $\begin{array}{c}\text { Pembayaran } \\
\text { Kemudian }\end{array}$ \\
\hline 1 & Amaq Run & $\sqrt{ }$ & \\
\hline 2 & Resah & $\sqrt{ }$ & \\
\hline 3 & Kecan & & $\sqrt{ }$ \\
\hline 4 & Ilham A & $\sqrt{ }$ & \\
\hline 5 & Anten & & $\sqrt{ }$ \\
\hline 6 & Amaq Keli & & $\sqrt{ }$ \\
\hline 7 & Samsudin & $\sqrt{ }$ & \\
\hline 8 & Rim & $\sqrt{ }$ & \\
\hline 9 & Sun & $\sqrt{ }$ & \\
\hline 10 & Amaq Ayu & & $\sqrt{ }$ \\
\hline 11 & Abdul Manan & $\sqrt{ }$ & \\
\hline 12 & Airani & $\sqrt{ }$ & \\
\hline 13 & Imin & & $\sqrt{ }$ \\
\hline 14 & Kinum & $\sqrt{ }$ & \\
\hline Jumlah & & 9 & 5 \\
\hline $\begin{array}{l}\text { Perse } \\
\text { Ntase }\end{array}$ & & $64 \%$ & $36 \%$ \\
\hline
\end{tabular}

\section{KESIMPULAN}

Dari hasil analisis yang dilakukan, diperoleh data bahwa tingkat pendapatan petani dalam kisaran waktu 1 tahun adalah sebesar Rp. 2.901.000, rata-rata tiap kali panen dalam kisaran waktu perdua bulan sebesar Rp. 792.000 .

Dari hasil analisis R/C Ratio atau alat yang digunakan untuk mengukur nilai kelayakan suatu usaha yang dijalankan diperoleh nilai sebesar $2,58 \geq 1,3$, jadi dapat disimpulkan bahwa usaha kayu putih di Desa Montong Sapah dapat dikatakan layak untuk dikembangkan untuk usaha sampingan.

Dari hasil analisis pemasaran menunjukkan bahwa petani menjual kayu putih ke satu tempat (monopoli) dengan 2 sistem pembayaran yang dilakukan oleh pihak pembeli yaitu $64 \%$ pembayaran langsung dan $36 \%$ pembayaran kemudian.

\section{SARAN}

1. Untuk meningkatkan pendapatan maka diharapkan petani meningkatkan usaha pemeliharaan seperti pemangkasan (prunning) sesuai petunjuk teknis,

2. Perlu adanya campur tangan pemerintah untuk menentukan harga jual daun kayu putih 
3. Mencari informasi pasar untuk mendapat nilai jual maksimal atau optimal

4. Frekuensi kerja penyuluh lebih ditingkatkan kembali.

\section{DAFTAR PUSTAKA}

Adiwidjaja, R. 1969. Tinjauan Singkat Pengusahaan Kayu Putih Pada Dua Kelas Pengusahaan Hutan Jawa Barat. [Skripsi].Bandung.

Anonim, 1999. Undang-Undang Republik Indonesia Nomor : 41 Tahun 1999 Tentang Kehutanan.

Anonim. 2007. Peraturan Menteri Kehutanan Nomor : P.35 / Menhut-II/2007 Tentang Hasil Hutan Bukan Kayu.

Anonim. 2009. Peraturan Menteri Kahutanan Republik Indonesia Nomor : P. 19/MenhutII/2009 Tentang Strategi Pengembangan Hasil Hutan Bukan Kayu Nasional.

Dr.Noor Khomsah Kartikawati, S.Hut, MP, dkk. 2014. Budidaya dan Prospek Pengembangan Kyu Putih (Melaleuca cajuputi). IPB Press.

Guenther, E.1990. Minyak Atsiri. Jilid III. Diterjemahkan oleh Ketaren. Universitas Indonesia. Jakarta.

Hermanto S., Dwi W., 2006. Dampak Pertumbuhan Ekonomi Terhadap Penurunan Miskin di Indonesia: Proses Pemerataan dan Kemiskinan. Direktur Kajian Ekonomi. Institusi Pertanian Bogor.

Ilmu-ilmu Teknik dan Biologi. CV Armico. Bandung.

Rimbawanto A,Kartikawati NK, Prastyono. 2017. Minyak Kayu Putih: Dari

Salaka, F. J. Nugroho, B. \& Nurrochmat, D. R. 2012. Strategi Kebijakan Pemasaran Hasil Hutan Bukan Kayu di Kabupaten Seram Bagian Barat, Provinsi Maluku. Jurnal Analisis Kebijakan Kehutanan, 9 (1), 5065.

Soekartawi. 1986. Ilmu Usaha Tani dan Penelitian Untuk Pengembangan Petani Kecil. UI-Press, Jakarta.

Sudarmalik, Rochmayanto Y, Purnomo. 2006. Peranan Beberapa Hasil Hutan Bukan Kayu (HHBK) di Riau dan Sumatera Barat. Prosiding Seminar Hasil Litbang Hasil Hutan 2006: 199-219.

Sugiyono, D.R. (2009). Metode Penelitian Kuantitatif. "kualitatif dan R\&D." Bandung: Alfabeta.
Surakhmad, Winarno. 1982. Pengantar Interaksi Belajar Mengajar, Dasar dan Teknik Metodologi Pengajaran. Bandung : Tarsito.

Tanjung F.M. 2014. Kontribusi Hutan Rakyat Terhadap Pendapatan Usaha Tani Di Desa Bayasari, Kecamatan Jatinegara, Kabupaten Ciamis, Jawa Barat [skripsi]. Bogor (ID): Departemen Manajemen Hutan. Fakultas Kehutanan IPB. 